\title{
An observing response analysis of fixed ratio discrimination
}

\begin{abstract}
Two pigeons were trained on an observing response procedure where a peck to the observing key produced either a stimulus correlated with FR10 or FR50. When observing response output had become stable on this schedule, the lower of the two FRs was raised to 20 and then to 30 . The larger of the two FRs remained at 50. Both Ss ceased making the observing response when the lower FR was set at 30 。
\end{abstract}

\section{Problem}

Wyckoff (1952) and Kelleher (1958) have shown that observing responses which produce non-differential stimuli undergo extinction. In those experiments the non-differential condition consisted of having both stimuli paired with both reinforcement contingencies. In Wyckoff's study, for instance, there were two reinforcement contingencies, FI and extinction, and two different key colors. During the original training an observing response produced one of these two stimuli in such a way that one of the key lights was always correlated with FI and the other with extinction. In the non-differential condition neither key color was consistently paired with either of the schedules.

Another way to make the stimuli non-differential would be to use two stimuli, but only one schedule of reinforcement. In the present study, observing responses produced stimuli correlated with one of two schedules. As the lower FR is gradually raised, approaching the larger, the schedules become more and more similar, approaching the condition where only one FR is present. The object of the study was to determine if observing response output would be a sensitive index of discrimination between two fixed ratios.

\section{Method}

The Ss were two White King pigeons, run at $80 \%$ of free-feeding weight. The birds were experimentally naive at the outset of the experiment.

The experimental apparatus has been described before (Kendall, 1964). It consisted of a two-key pigeon chamber and associated control and recording apparatus. Food responses were recorded on a cumulative recorder and reinforcements and discriminative stimuli were recorded on an event recorder.

Several steps were taken in training the Ss. These were: (1) Key training (by successive approximation) and continuous reinforcement; (2) training of an FR10; (3) training on a mixed FR10 FR50 schedule. During these three stages there were no lights illuminating either response key and the observing key was not operative. The next stages were: (4) multiple schedule training and (5) observing response training. The multiple schedule was mult FR10 FR50. During FR10 a red light illuminated the response key and during FR50 a blue light. The procedure for training the observing response has been described elsewhere (Kendall, in press). Briefly, it consisted of giving a few reinforcements for pecks to the observing key and then discontinuing reinforcement. When the reinforcement was discontinued the only contingencies for a peck to the observing key became the illumination of the food key for $5 \mathrm{sec}$. with the color of the FR currently programmed. The stimulus duration remained at $5 \mathrm{sec}$. throughout the experiment and the observing requirement was kept at FR1.

The Ss were exposed, until observing response output was stable, to food schedules of FR10 FR50, FR20 FR50 and FR30 FR50 in that order. Stabilization was usually achieved within 30-40 sessions. A session lasted until a $\mathrm{S}$ had collected enough $3.5 \mathrm{sec}$. grain reinforcement to maintain his weight. This number ranged between 70-100.

\section{Results}

The results of the experiment are presented in Fig.1. The data are in terms of an observing ratio (Kendall, 1965). The ratio is formed by dividing the number of

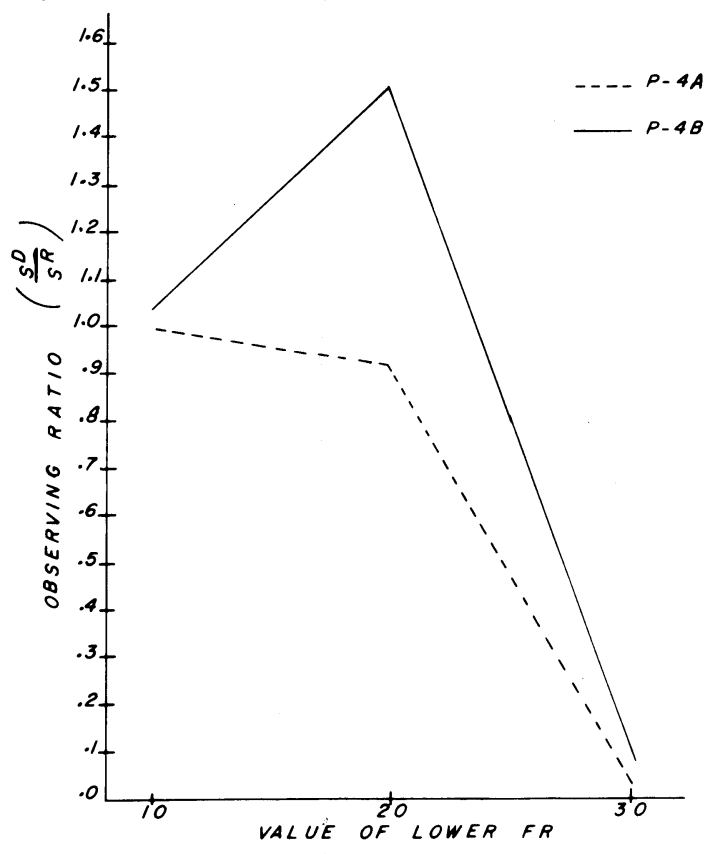

Fig. 1. Observing ratio as a function of the value of the lower FR. The larger FR was kept at FR50. 
discriminative stimuli produced by the $\mathrm{S}$ by the number of food reinforcements. A ratio of 1.00 indicates one observing response per reinforcement. All data presented represent means of the last four days of data collection under a given condition.

The functions are different for the two Ss. This is mainly because of the high observing response output for P-4B at FR20 FR50. This high output is due to the regular emission of two observing responses during FR20. The event records showed that both birds made observing responses after reinforcement, before responding on the food key again. P-4A was able to run through FR20 within 5 sec. after he had made an observing response. P-4B did not do this and interrupted the FR20 in order to make another observing response. Inspection of the event records indicated that both birds infrequently made two observing response during FR50, although FR50 could not be completed within $5 \mathrm{sec}$.

Both birds give approximately the same observing ratios at FR10 FR50 and FR30 FR50. Observing behavior is strong at FR10 FR50 and very weak at FR30 FR50.

\section{Discussion}

The original plan of the experiment had been to increase the value of the lower FR to 30 in steps of 10 and then raise it in smaller steps. It was expected that as the lower FR was increased, the observing ratio would show a systematic decrease, eventually falling off to 0 . The original plan of the experiment was impossible to carry out since the observing ratio fell nearly to zero when the lower FR reached FR30.
Another study of ratio discriminability (Rilling \& McDiarmid, 1965) found that pigeons can easily discriminate between FR35 and FR50. In fact, fair discrimination was shown between FR45 and FR50。 It is evident that in the present experiment the discriminative stimuli lost their reinforcing power before discrimination between the two schedules broke down.

The fact that pigeons are able to discriminate between two FRs does not mean that they will under all circumstances. In an observing response experiment discrimination does not increase the probability of reinforcement (Wyckoff, 1952, 1959). In retrospect, it is not surprising that the Rilling and McDiarmid experiment yields quite different results from the present experiment. In their experiment reinforcement was contingent on discriminative behavior whereas in the present experiment the observing response only provides information as to which schedule is currently present.

\section{References}

Kelleher, R. T. Stimulus-producing responses and attention in the chimpanzee. J. exp. Anal. Behav., 1958, 1, 87-103.

Kendall, S. B. Fixed interval behavior in mixed and multiple schedules with alternating fixed interval-fixed ratio components. Psychon. Sci., 1964, 1, 165-166.

Kendall, S. B. The distribution of observing responses in a mixed FI-FR schedule. J. exp. Anal. Behav., in press.

Kendall, S. B. Competing behavior and observing responses. Psychon. Sci., 1965, 3, 279-280

Rilling, M., \& McDiarmid, C. Signal detection in fixed-ratio schedules. Science, 1965, 148, 526-527.

Wyckoff, L. B., Jr. The role of observing responses in discrimination learning: Part I. Psychol. Rev., 1952, 59, 431-442.

Wyckoff, L. B., Jr. Toward a quantative theory of secondary reinforcement. Psychol. Rev., 1959, 66, 68-78.

\section{Errata}

KASPER, PHYLLIS. Disruption of position habit reversal by septal stimulation. Psychon. Sci., 1965, 3, 111-112-In the 2nd paragraph under Procedure, line 6, it should read "at $20 \mathrm{a}$ "; in the 1st column of page 112, line 12, "Zucker \& McCleary's (1964)"; and the label on the abscissa of Fig. 2 should be "Days."
ROUTTENBERG, A. The effects of chemical stimulation in dorsal midbrain tegmentum on self-stimulation in hypothalamus and septal area. Psychon. Sci., 1965, 3, 41-42-The third to the last line of the Method section should read " ... study, carbachol, choline chloride, and carbachol were..." 